\title{
QUANDO O SER HUMANO CRIA, IKU VEM À TERRA: AS MEDIAÇÕES DE EXU, A ONIPRESENÇA DA MORTE E A COVID-19 EM DOIS CONTEXTOS AFRORRELIGIOSOS
}

When the human being creates something, Iku comes to the earth: Eshu's mediation, the omnipresence of the death and the Covid-19 at two Afican Brazilian religious contexts

Cuando el ser humano crea, Iku viene a la tierra: las mediaciones de Eshú, la omnipresencia de la muerte y la Covid-19 en dos contextos religiosos afro-brasileños

VÍTOR QUEIROZ ${ }^{*}$

DOI: https://doi.org/10.1590/S2178-149420210205

'Universidade Federal do Rio Grande do Sul - Porto Alegre (RS), Brasil.

*Professor do Departamento de Antropologia da Universidade Federal do Rio Grande do Sul, pesquisador do Núcleo de Estudos da Religião e do Núcleo de Antropologia das Sociedades Indígenas e Tradicionais (queiroz.avila@ufrgs.br).

(D) https://orcid.org/0000-0003-1735-4203

Artigo recebido em $1^{\circ}$ de janeiro de 2021 e aprovado para publicação em 23 de março de 2021. 


\title{
RESUMo
}

Este artigo propõe-se a pensar a reação dos cultos afro-brasileiros à pandemia da COVID-19. Em vez de generalizações, porém, o presente texto procura desdobrar alguns momentos etnográficos específicos, localizados em dois contextos, o Rio Grande do Sul e a Bahia, e possibilitados por mediações online. Sendo um dos primeiros resultados de uma pesquisa em andamento - que tematiza a agência de Exu, divindade do movimento e da comunicação, nessas localidades - , o artigo procura evidenciar, também, alguns aspectos da intensa reflexão prático-conceitual sobre mediação, diferença e cuidado que atravessa tais religiões e que tem chamado a atenção da bibliografia específica recente.

PALAVRAS-CHAVE: Religiões Afro-brasileiras; Coronavírus; Exu; Diferença e Mediação; Etnografia Online.

\begin{abstract}
This article aims to reflect upon African-Brazilian cults' reactions to the Covid-19 outbreak. Instead of making generalizing statements, however, this text seeks to unfold some specific ethnographic moments that have been located in two different contexts - the southern Brazilian state of Rio Grande do Sul and the northeastern state of Bahia — through an online fieldwork experience. As one of the first results of a research in progress about Eshu, a powerful divinity that deals with movement and communication, it will additionally discuss the ideas of mediation, care and difference that characterize those religions and which attracted the attention of the recent specific bibliography.
\end{abstract}

KEYWORDS: African Brazilian Cults; Coronavirus; Eshu; Difference and Mediation; Online Ethnography.

\section{RESUMEN}

Este ensayo intenta hacer una reflexión sobre cómo las religiones afro-brasileñas reaccionaron a la pandemia de la Covid-19. Sin embargo, en lugar de generalizaciones este texto ofrece descripciones de algunos momentos etnográficos específicos ubicados en dos contextos regionales - los estados brasileños de Rio Grande do Sul y Bahía - mediante una experiencia de trabajo de campo online. Como uno de los primeros resultados de una investigación en curso sobre Eshu, poderoso dios de las transformaciones y de la comunicación, el ensayo también va a abordar las ideas de mediación, cuidado y diferencia que caracterizan el pensamiento de estas mismas comunidades religiosas.

PALABRAS CLAVE: Religiones Afro-brasileñas; Coronavirus; Eshu; Diferencia y Mediación; Etnografía Online. 


\section{AVAMUNHA}

\section{O BATUQUE EM ÉPOCA DE PANDEMIA}

Dai Tiago de Bará Onilú e Ricardo Sordi de Oxalá faziam, no dia 21 de abril de 2020, a pri1 meira live deles, intitulada "O batuque em época de pandemia", para o jornal Grande Axé (Martins e Sordi, 2020)². Logo no início, ambos citaram o Decreto n² 20.534, de 31 de março de 2020, no qual a prefeitura de Porto Alegre instituía o estado de calamidade pública na cidade, proibindo, entre outras medidas, a aglomeração de mais de 30 pessoas em eventos religiosos, observando-se ainda um "distanciamento mínimo de 2 metros entre cada um dos presentes" (Porto Alegre, 2020, art. 19), assim como as decisões estaduais a respeito. Alguém que assistia à live perguntou, então, se poderia realizar uma cerimônia "obedecendo ao limite de pessoas" . Apelando para o "bom senso", Pai Tiago tentou dissuadi-lo desta maneira:

Ó, daí a gente entra naquela coisa de lei e questão de religião, tá? Basta uma pessoa contaminada dentro do ambiente para contaminar todos que estão lá. Então é a questão do bom senso, em primeiro lugar. Isso tanto na umbanda quanto no batuque, pessoal. A gente não pode ter o espaçamento, cada um sabe, pelo fundamento da sua casa, porquê. Não podemos usar máscara, nós precisamos cantar, nos expressar e muito mais... e, mais ainda, se a gente tiver com as divindades ou as entidades manifestadas, entendeu? Não tem como fazer isso (Martins e Sordi 2020).

Conforme veremos neste artigo, esta convergência entre lei e religião não é exatamente unificadora e não cancela nem as dualidades, nem as diferenças. Pelo contrário, ela só pode existir pela diferença. A impossibilidade de realizar uma gira de umbanda ou uma festa pública de batuque envolve, afinal, a agência das divindades. Além da alteridade radical que o patógeno da COVID-19 trouxe à tona, o bom senso de Pai Tiago leva em conta outros modos de ser, outros domínios incomensuráveis:

Os caboclos, as entidades em geral, Exus, os pretos velhos, todos os orixás, eles se cumprimentam. Basta uma pessoa contaminada pra contaminar todas as outras. Não é porque a pessoa está com manifestação [que ela está imune ao coronavírus]... indiferente à questão de tu estar de máscara ou não.

Pega tipo o caboclo que eles fazem assim e se abraçam. Gente, bastou [isso] pra tá contaminado, tá? E, se tu pega, leva as vezes vinte dias pra doença tá manifestada... os sintomas, né? Então tu pode tá preparando um alimento, tu pode tá tocando em coisas [e contaminando os outros sem saber] (Martins e Sordi 2020).

Todos os temas deste artigo já aparecem nessa resposta curta e enfática. A ética do cuidado que ela demonstra, que opera em muitos níveis ${ }^{3}$ e que se manifesta cotidianamente 
nas comunidades de terreiro por meio de uma atenção constante à convivência entre os entes e as coisas, os seres humanos e não humanos - convivência que sempre implica afetos, contaminações e transformações recíprocas - , será desdobrada e discutida, ainda que em caráter preliminar, ao longo do presente trabalho. Antes de seguir adiante, voltemos rapidamente à live do Grande Axé.

\section{PENSAR A DIFERENÇA}

Dai Tiago - que havia me convidado, via WhatsApp, para assisti-la —, além de ser tamboreiro e pai de santo, preside uma das entidades destinadas à proteção das religiões afro-brasileiras no Rio Grande do Sul, a Associação Independente em Defesa das Religiões Afro-Brasileiras (Asidrab). Ricardo Mesquita Sordi apresenta-se publicamente como "advogado de família e cacique de umbanda". A posição deles, portanto, vinha de vários lados e respaldava firmemente tanto os decretos relativos ao "enfrentamento da pandemia do novo Coronavírus" (Porto Alegre, 2020, art. $1^{\circ}$ ) vigentes, quanto as prescrições da Organização Mundial da Saúde (OMS). Em algum momento da live, o pai de santo resumiu-a desta forma: "a gente tem que se preservar e preservar os nossos, para que a gente possa dar continuidade [às nossas religiões], sabe?" (Martins e Sordi, 2020). 0 Grande Axé, um importante veículo de imprensa ligado aos cultos afro-brasileiros na região (Mateus, 2017: 263), mantinha uma postura semelhante em sua página de Facebook. Sua foto de capa trazia, desde o início da pandemia, estas frases: "Todos juntos na luta contra o Coronavírus" e "Tudo passa!".

Lado, além do seu significado habitual, carrega outros sentidos neste ensaio. Ainda que os praticantes do batuque gaúcho se refiram a eles mesmos como "de Nação", frequentemente aquilo que outras religiões afro-brasileiras chamam de nação ${ }^{4}$ também é chamado de lado no Rio Grande do Sul. Porém tal palavra não deve ser entendida apenas como um simples demarcador de fronteiras na linguagem do parentesco religioso. Essa ideia, que permeia tais religiões, deve ser tratada como um conceito, caso apostemos na tentativa de "pensar outro pensamento" (Viveiros de Castro, 2002: 132) visando, em síntese, a "uma atualização das virtualidades insuspeitas do pensar" (Viveiros de Castro, 2002: 129).

Tal concepção parece indicar, entre outras coisas, a precedência de um estar sobre um ser (Dos Anjos, 2008). De modo geral, nesses cultos variados, utiliza-se muito a noção de que não só as coisas (objetos, pessoas ou entidades) têm vários lados, sendo potencialmente boas ou ruins a depender de uma série de circunstâncias, mas também que os limites entre seus diversos estados ou instanciações são pouco definidos, sendo constantemente deslocados (Cf. Cardoso e Head, 2015). Em resumo, tudo depende de posição, relação e conjuntura para o povo de axé. 
Como sugerem as falas de Pai Tiago, nem mesmo o corpo ou a pessoa ${ }^{5}$ dos adeptos - que passa por longos processos de construção, estando menos na ordem do dado que do feito (Goldman, 2012) - forma uma unidade estável e invariante. Por um lado, "as divindades ou entidades" (Martins e Sordi, 2020) manifestam-se em corpos humanos sem perder sua alteridade. Por outro, ainda que o transe seja um estado de possessão, os espíritos ou entes divinos ocupam-nos de forma intermitente. Em outras palavras, o ser do fiel nem desaparece no transe, que costuma ocorrer apenas em momentos ritualmente delimitados, nem converge para uma identidade individual e singular, mas é produzido na relação com suas entidades protetoras, a partir e através da diferença. Seu corpo físico participa, inclusive, dessas conexões o tempo todo, com suas afecções, seus processos biológicos e a possibilidade de ser afetado por tipos mais perigosos e descontrolados de manifestação — a da COVID-19, por exemplo.

Dias antes da live de Pai Tiago e de Ricardo, um artigo assinado por dois especialistas em antropologia da religião havia saído num jornal renomado (Almeida e Guerreiro, 2020). Nele, "as religiões de matriz afro-brasileira" (Almeida e Guerreiro, 2020) aparecem, ao lado de outros credos, em contraponto a algumas das maiores congregações neopentecostais do país que resistiram ao cancelamento de seus cultos, "sem considerar [o] bem-estar" (Almeida e Guerreiro, 2020) de seus fiéis ante o coronavírus. Outras notícias se seguiram. Algumas delas fazem, direta ou indiretamente, a mesma comparação. Outras, veiculadas pelos próprios afrorreligiosos e seguidas de comentários indignados, dedicam-se a denunciar, encarando-as como exceções, cerimônias clandestinas em alguns terreiros. Todas elas reforçam a opinião da Asidrab e do Grande Axé, deixando evidente que, apesar desses casos desviantes, tais religiões, ironicamente consideradas pré-modernas por muitos brasileiros, têm lidado de forma aparentemente sensata com a pandemia.

Isolado socialmente desde o dia 16 de março, escrevo este primeiro relato de uma etnografia realizada com o povo de axé nos últimos meses, sem o intuito de responder diretamente à pergunta implícita nesta introdução — por que tais comunidades religiosas têm defendido os decretos emergenciais de seus estados ou municípios e as diretrizes sanitárias internacionais, adaptando-se relativamente bem à nova situação gerada pela pandemia —, num ímpeto generalizante. Da mesma forma, não recorrerei a uma análise devedora das ideias de mercados religiosos em disputa ou de instituições religiosas - com seus conjuntos de correspondências mítico-rituais, liturgias ou tipologias sociais mais ou menos estabilizadas — e muito menos de quaisquer noções de castigo sobrenatural ou expiação.

Tentarei, pelo contrário, mobilizar, com base em uma experiência de pesquisa incipiente e localizada — ainda que de forma sui generis — , determinadas práticas e conceitos que 
integram essas religiões para pensar tal questão. Para tanto, além da noção de lado e das práticas rituais que implicam a manutenção da diferença entre seres humanos e não humanos, elementos que já foram esboçados com base nas falas de Pai Tiago sobre a COVID-19, farei referências às elaboradas ideias de mediação e aliança que atravessam os cultos afro-brasileiros como um todo, por meio da agência de Exu — poderoso orixá que atua como o intermediário por excelência — - e, finalmente, ao posicionamento que o povo de santo costuma ter em relação à morte.

Evidentemente, os enredos ${ }^{6}$ que associam os afrorreligiosos a entidades como a COVID-19, Exu e a morte, e, numa escala muito menor, às minhas atividades etnográficas vinculam-se a uma série bastante ampla de temas e percepções. Para tornar alguns desses conteúdos inteligíveis, antes de enveredar por uma breve discussão conceitual, apresento uma descrição do início do meu trabalho de campo. Dessa forma, retrato nas próximas páginas a minha inserção em dois contextos diferentes, a modalidade online de etnografia a qual recorri nos últimos meses e que talvez tenha uma duração mais longa do que se esperava inicialmente $^{7}$ e, sobretudo, as relações de afeto que possibilitaram minhas interações de pesquisa ou tornaram-se possíveis por meio delas. No fim do texto, darei meia-volta e tentarei retornar pelo mesmo caminho, passando inversamente da metafísica afrorreligiosa às interações singulares com meus parceiros de pesquisa.

\section{NA RUA, NO MEIO DO REDEMOINHO}

o dia 15 de março, eu havia chegado de viagem. Vinha de Porto Alegre para Campi-
nas, onde morava naquele momento. A pesquisa que eu planejava fazer há tempos havia começado de forma abrupta. Tinha em mente não só produzir um estudo sobre uma entidade de origem oeste-africana, Exu, mas também com ela, adotando-a, por meio de seus efeitos, afetos, símbolos e indícios (Strathern, 1999; Siqueira, 2005 [1990]; Turner, 1970 [1969]), como um agente e um ponto de vista privilegiado.

Essa entidade, cultuada em praticamente todas as religiões afro-brasileiras, parece estar em toda parte. Exu, mais conhecido no Sul como Bará8, deve ser assentado ${ }^{9}$, obrigatoriamente, nas entradas de cada terreiro e, nas casas de religião gaúchas, ele é o único orixá a ter uma habitação em separado (Machado, 2015; Corrêa, 1992). Exu deve ser lembrado antes de qualquer atividade ritual, recebendo a primeira porção de tudo aquilo que é ofertado aos outros deuses (Verger, 1981 [1951]; Santos, 1976 [1972]). Ele também ocupa os espaços públicos sendo, em todo esse espectro afrorreligioso, considerado o dono da rua e das encruzilhadas em pelo menos dois níveis complementares. Como entidade da potência inco- 
mensurável e do movimento, ele é o deus que se encontra nos locais agitados, sendo também o responsável pelas dinâmicas de encontro, confronto e dispersão de coisas e pessoas, pela abertura e fechamento das possibilidades, dos destinos e dos caminhos.

Em Santo Amaro da Purificação, uma pequena cidade do Recôncavo Baiano, e, bem distante dali, na populosa capital do Rio Grande do Sul, a presença de Exu e de Bará assume uma forma particularmente concreta e tangível. Nessas duas localidades, o batuque gaúcho e o candomblé baiano são exteriorizados ostensivamente em espaços comerciais históricos, situados no centro de seus respectivos municípios. Nesses municípios, nosso orixá está entremeado em uma rica história local, vale dizer, em uma história performática (Mattos e Abreu, 2016) e dotada de uma temporalidade própria que é cuidadosamente mantida e reproduzida por suas respectivas comunidades de terreiro.

No Mercado Público de Porto Alegre, um assentamento de Bará medeia uma série de relações, e, em Santo Amaro, o Mercado Municipal é tomado anualmente pelo ritual do Bembé, uma enorme festa de candomblé a céu aberto que dura três dias e ocorre sempre numa data próxima ao dia 13 de maio. Exu também protagoniza essa cerimônia (Oro et al., 2007; Machado, 2009). A pesquisa tratar-se-ia, portanto, de uma etnografia comparativa posicionada numa fronteira analítica sugerida pelas qualidades dessa entidade, perguntando-se como se dá a inter-relação entre tais religiosidades e a produção/fluxo de mercadorias, pessoas e memórias nessas duas localidades.

Tive que ir para Porto Alegre, por outros motivos, na semana imediatamente anterior ao agravamento da crise causada pelo coronavírus no Brasil. Entre a minha partida e minha volta para Campinas, onde morava na época, telefonei para alguns pais de santo gaúchos, encontrei-os, li muito, dormi pouco, assisti, também convidado por Pai Tiago, a uma audiência pública sobre "a condição de Patrimônio Cultural do Mercado Público" (TV ALRS, 2020) da cidade na Assembleia Legislativa do Rio Grande do Sul — onde, aliás, pude encontrar uma amostragem impressionantemente rica das redes que são atravessadas pelo Bará e que deverei seguir ao longo da pesquisa, de afrorreligiosos, representados por Yá Vera Soares de Oyá Lajá, comerciantes e políticos às autarquias como o Tribunal de Contas da União (TCU) e o Instituto do Patrimônio Histórico e Artístico Nacional (IPHAN) - e percorri o centro da capital gaúcha muitas vezes, na companhia de alguns membros da comunidade negra local. A abertura simultânea de tantos caminhos e o ímpeto com o qual esse campo improvisado emergiu impressionaram-me. Voltei para casa, em contraste, com o fechamento de tudo e as primeiras medidas de isolamento social. Se as passagens aéreas tivessem sido agendadas para a semana seguinte, minha viagem sequer existiria e esta etnografia ainda não teria começado. 
Dois dias depois, Pai Paulinho de Xoroquê, um dos sacerdotes que havia conhecido e que é o atual responsável pelos rituais públicos que envolvem o Bará do Mercado, enviou-me pelo WhatsApp uma fotografia com múltiplas estátuas de Obaluaê, orixá das doenças e da cura, e de outras entidades relacionadas a ele. As imagens, postas num dos cômodos do seu terreiro, vinham acompanhadas por uma benção. Reproduzo-as tal como as recebi (Figura 1).

Dessa forma, além de preocupar-se com a minha saúde e de ser gentil, Pai Paulinho reforçava nosso vínculo recém-estabelecido, mantendo as portas de seu ilêto abertas para mim. Em seguida, entrei em contato com meus outros parceiros humanos de pesquisa, apenas para saber como eles estavam. Para minha surpresa, uma fase nova e movimentada da minha etnografia surgiria dessas mensagens despretensiosas. É claro que eu havia planejado ir a Santo Amaro em maio, para assistir ao meu primeiro Bembé e começar meu trabalho de campo por lá. Porém, esse segundo plano de viagem tornava-se cada vez mais irrealizável à medida que as semanas iam passando.

Por alguns momentos, interromperei a narrativa desses e de outros imponderáveis etnográficos. Farei a seguir uma rápida discussão conceitual, a fim de apresentar, de forma incipiente, algo da intensa reflexão indissociavelmente prática e metafísica que atravessa tais religiões. Em outras palavras, nas próximas duas seções deste ensaio, as relações de

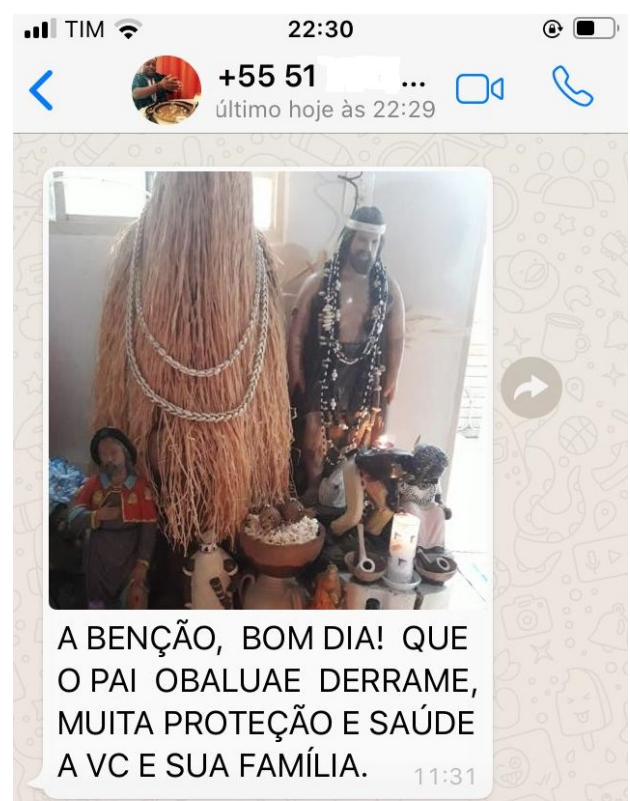

Figura 1 - Obaluaê, São Roque, São Lázaro e dois Pretos Velhos. Ilê Axé Ogunjá Agadá, Porto Alegre. Imagem recebida via WhatsApp em 18 de março de 2020 (captura de tela). 
figura e fundo da minha argumentação serão invertidas. Começo este détour com uma descrição mais detalhada de Exu, o mediador por excelência que é, afinal, entre muitas outras coisas, meu tema de estudo.

\section{EXU VOLTA DO MERCADO...}

Bára je n’tan á nló

Bára je n’tan máa ló ilé

Bará já comeu, está satisfeito Bará já comeu, está indo para casa."

E xu possui todas as características de um trickster. Seus mitos exploraram, por vezes até às últimas consequências, a sua atividade incessante, sua moralidade ambígua e seu papel de mediador estrutural entre categorias sensíveis e inteligíveis (Cf. Lévi-Strauss, 2008 [1955]). Já seus orikis (saudações) louvam sua dubiedade ("Exu faz o erro virar acerto e o acerto virar erro") e seus poderes inconcebíveis ("Exu volta do mercado trazendo óleo numa peneira").

Além disso, assim como os décepteurs — outra denominação lévi-strausseana para essas mesmas entidades ambivalentes (Lévi-Strauss, 2008 [1955]) ${ }^{12}$ —, Exu costuma levar suas prodigiosas atividades de mediação e interseção muito longe. Ele não é somente um veículo, um simples intermediário entre unidades discretas - sejam elas entidades, categorias ou os próprios destinos, os caminhos percorridos por cada coisa - mas também promove 0 cruzamento dinâmico de tudo isso, "produzindo deslocamentos, traduções e transformações ao longo do percurso" (Rabelo 2012: 105; cf., também, Latour, 2002). A simples presença de um trickster ou décepteur costuma introduzir, na própria forma dos mitos, uma série de descontinuidades, detalhes e episódios heterogêneos, seguidos de encadeamentos novos e inusitados, dando a eles, portanto, um caráter rapsódico:

Os mitos que têm este tipo de personagem como herói são frequentemente construídos como um mosaico, por meio de encadeamentos recíprocos de fragmentos de cadeias sintagmáticas provenientes de mitos distintos, quando não opostos. Resulta daí uma cadeia sintagmática híbrida, cuja própria construção traduz, por sua ambiguidade, a natureza paradoxal do enganador [décepteur] (Lévi-Strauss, 2004 [1967]: 179).

Para Lévi-Strauss, portanto, além de protagonizar determinadas narrativas ou fornecer um conteúdo a mais para o desenvolvimento dos enredos míticos, o décepteur é, sobretudo, um 
notável enredador. Ou seja, ele é um poderoso operador que produz sentido onde não havia, unindo conteúdos e pontas soltas — ou, para utilizar uma metáfora corrente nos meios afrorreligiosos, especialmente na umbanda, fazendo amarrações firmes —, colocando-as em relação por meio de um jogo intrincado de recombinações, justaposições e analogias.

Exu é, finalmente, o deus da própria comunicação, da linguagem e da fala. Sem a sua mediação como mensageiro, tradutor e intérprete universal, o seu trânsito incessante entre os domínios de cada um dos deuses e entre estes, os humanos e todos os outros entes, a efetivação de qualquer coisa, assim como o sentido e a cognição de qualquer realidade ficariam comprometidas. Porém, afastando-se ligeiramente do estruturalismo lévi-strausseano, nosso décepteur possui certamente um caráter duplo, mas não exatamente polarizado, dicotômico ou binário. Robert Pelton, num estudo detalhado sobre os tricksters divinos em contextos oeste-africanos, sugere que, para os yorubás, a atuação de Exu é verdadeiramente cósmica, ou seja, que ela compreende a totalidade das coisas.

Essa totalidade liminar e transicional não cancelaria as oposições. Pelo contrário, ela estaria entremeada de transformações e paradoxos, da convivência simultânea de domínios e disposições contrárias:

Seu sentido está menos enraizado na coincidência dos opostos ou meramente na passagem entre estruturas e antiestruturas do que na percepção da vida como uma totalidade circular cujas faces tanto mascaram quanto desvendam umas às outras. Essas faces são simultâneas, mas tal simultaneidade é processual, é um giro por meio do qual uma face não apenas sucede, mas se transforma na outra (Pelton, 1980: 104, tradução própria).

Voltando ao meu relato etnográfico, apesar de saber teoricamente dessas qualidades assombrosas de Exu, não imaginava que, na prática, a pesquisa com esse grande intermediário envolvesse, de saída, tantos encadeamentos simultâneos. Tais vínculos foram possibilitados por um número relativamente pequeno de interfaces, dispostas sobre três eixos inter-relacionados. De um lado, a dupla mediação dos dispositivos eletrônicos e da própria pandemia que habilitaram e impulsionaram, no meu caso, uma nova modalidade de campo, online, intermitente, porém intensa, caracterizada por inúmeras lives, videochamadas, imagens e, principalmente, áudios compartilhados via WhatsApp. Do outro, o próprio caráter concreto, mediador e articulador de dimensões diversas, efetivado no idioma da troca e da aliança, que tipifica os cultos afro-brasileiros - e que tem ocupado recentemente a bibliografia específica (Sansi, 2005; Goldman, 2012; Johnson, 2002) —-, parecia fornecer, para o povo de axé, categorias de entendimento adaptáveis à nova situação. $E$, entre contingências e estruturas, minha rede virtual de pesquisa montou-se com uma agilidade ímpar, através de encargos modestos e, sobretudo, da confiança mútua. 
Foi assim, por exemplo, que, estabelecendo contato com Darlei Sacramento, de Santo Amaro, por intermédio de amigos ligados ao ensino universitário local, pude acessar uma série interminável de contatos, fotos e documentos oficiais, além de vivas descrições da cidade durante todo o mês de maio. Darlei é filho de santo de um dos terreiros que organiza o Bembé, percussionista e estudante de ciências sociais. Contudo, nem o manejo habilidoso de dispositivos variados, nem essa prontidão em estabelecer alianças são incomuns nesse contexto afrorreligioso.

Todo despacho deixado numa esquina, por mais simples que seja, trata-se também, nesses cultos, de um dispositivo capaz de unir certos lados, posições ou estados normalmente dispersos das coisas para a consecução de um propósito ou como uma forma de agradecimento. Na verdade, a oferenda, esse rito elementar que geralmente assume a forma de uma doação de alimentos provenientes de um sacrifício prévio, já indica a importância e a necessidade da mediação entre domínios incomensuráveis (neste caso, entre animais, deuses e seres humanos) que é a base de tais religiões. Essas técnicas de mediação costumam, porém, estar cobertas de incertezas, sendo, justamente, regidas pelo travesso e contraditório orixá Exu.

Já a lenta construção da pessoa de um fiel ou mesmo de um orixá torna ainda mais evidente a centralidade que o manuseio de determinados apetrechos assume para o povo de santo. Tais apetrechos também operam como poderosos dispositivos mediadores, uma vez que eles são capazes de mobilizar presenças, corporificando-as e colocando-as em relação no tempo. Os objetos plantados, isto é, enterrados ou guardados cuidadosamente e que constituem o assentamento de alguém são, afinal, entes dotados de vida e de agência que devem ser encontrados na natureza — "no tempo", segundo o jargão do candomblé — e, após um ritual de consagração, transformam-se em verdadeiros corpos externos. A partir de então, os assentamentos passam a personificar seres humanos e não humanos específicos. Esses entes-objetos, essas coisas rodeadas de segredos e interditos estão, consequentemente, carregadas de historicidade, pois marcam momentos precisos da produção das pessoas e dos seus laços de parentesco religioso em sua "materialidade irredutível" (Pietz, 1985), mas também implicam negociações constantes, além de riscos e conflitos em potencial (Goldman, 2009; Sansi, 2005, 2009; Rabelo, 2012).

É possível afirmar, usando a terminologia fenomenológica de Heidegger ${ }^{13}$, que tais dispositivos e práticas rituais são análogos ao que esse filósofo definiu como Dasein, ou seja, a ideia de que as coisas, os entes, são contingentes e relacionais, são-no-mundo e são-com-os-outros (Heidegger, 2012 [1927]; Rabelo, 2012). De fato, o povo de axé parece habitar um mundo, uma ontologia na qual são as associações e as influências recíprocas que fazem os seres e suas disposições emergirem, e não o contrário, numa série sucessiva e mutável de contextos e ações- 
-escolhas cujo único limite equivale ao curso irrevogável "do tempo como o horizonte possível de todo entendimento-do-ser-em-geral" (Heidegger, 2012 [1927]: 31). Contudo, exatamente por conta disso, a necessidade de controle intensivo sobre a produção dos corpos "nem inteiramente autônomo[s], nem inteiramente construído[s]" (Latour, 2002 [1996]: 23) dos seres humanos e não humanos é uma fonte contínua de preocupação nessas religiões.

Em outras palavras, os múltiplos lados, as muitas possibilidades abertas pelas conexões variáveis e pelos estados transitórios das coisas (Cardoso e Head, 2015), sempre mantêm uma relação de potência e perigo. No Recôncavo, a maniçoba, um prato da culinária local que é vendido nas barraquinhas armadas durante o Bembé santo-amarense, consubstancializa exemplarmente tal relação. Por ser uma comida saborosa, esse caldo feito de folhas de mandioca brava, as manivas, cozidas com diversos tipos de carne, é muito procurado. Porém, muita gente - inclusive eu — evita consumi-la fora daquela região, de certos estabelecimentos já conhecidos e sem recorrer a uma rede ampla de informações, fianças ou respaldos. Como se diz na região, trata-se de uma "comida de respeito." Servir-se dela, consequentemente, é alimentar-se, também, de indícios, mediações e vínculos sociais, pois uma maniçoba mal preparada - aquela que não foi fervida ininterruptamente por muitos dias sucessivos para a retirada quase total do veneno das manivas - pode levar alguém à morte em poucas horas, com dores abdominais terríveis.

\section{O FIM DA VIDA}

Quando eu canto a morte me percorre e eu solto um grito da garganta e a cigarra quando canta morre e a madeira quando morre canta

Paulo César Pinheiro e João Nogueira

\footnotetext{
A s religiões afro-brasileiras têm um vínculo muito forte com os ancestrais e com a própria morte. São "religiões que equacionam a vida com a morte" segundo um de seus maiores estudiosos, Vivaldo da Costa Lima (2010: 287). "Na ideologia do candomblé" — ele prossegue - "a morte está presente na essência mesma da vida, desde o seu começo, e a vida, de sua parte, persiste, continua mesmo depois da morte. As transformações que marcam o desenvolvimento do ser vivo, prosseguem para além da sua morte" (Lima, 2010: 288). Mãe Manuela de Ogunjá, uma jovem ialorixá santo-amarense, por sua vez, concluiu sua fala sobre o Bembé deste ano numa live do dia 14 de maio - ou seja, em meio à cerimônia, caso ela tivesse ocorrido normalmente — dizendo algo parecido de forma vigorosa, mas bem-humorada:
} 
Vá pra lá, Iku [a Morte], leve tudo de ruim da minha vida! Eu estou falando com vocês, de Manuela de Ogunjá para vocês: boa sorte! Olhe gente, Abi [a Vida] que atue na vida de vocês, mas quando Abi atua, é... assim, de repentemente, baixe a cabeça pra Iku. Não existe vida sem morte, não existe o sim sem o não, às vezes o sim vem negar e às vezes o não vem afirmar, fica a dica. Ó, boa noite e axé pra todos! (Pereira e Portela, 2020).

Falar diretamente do pesar por aqueles que partem, ademais, não é nada excepcional para o povo de axé. Pelo contrário, ouvir comentários sentidos sobre um sacerdote ou um tio falecido foi uma constante nas conversas que tivemos nos últimos meses. Esta atitude dos afrorreligiosos de lembrar cotidianamente da morte faz com que, no pensamento desses cultos, parafraseando o humanista Michel de Montaigne (1996: 92), "aprender a morrer" seja algo extremamente importante. Além disso, os integrantes do batuque e do candomblé provavelmente concordariam com as afirmações mais severas do filósofo renascentista, como esta, por exemplo: "arranquemos as máscaras das coisas como das pessoas e, por baixo, veremos muito simplesmente a morte" (Montaigne, 1996: 105).

Porém, tanto para Montaigne quanto para Mãe Manuela e todos os meus parceiros de pesquisa, esse aprendizado, essa constatação aparentemente sinistra e a aceitação, em resumo, de que "[a] morte entra na própria organização do universo", que ela faz parte do "belo entrosamento das coisas" e que "a morte é parte integrante" da vida de cada um (Montaigne, 1996: 102) não recai num fatalismo sombrio. Nada disso impede que as religiões afro-brasileiras sejam festivas. Pelo contrário, nelas tudo é celebrado com muita animação, comida e música. Não seria possível, afinal, viver num mundo feito só de perigos, onde todas as manivas conduzissem-nos à cova.

Talvez seja por conta de percepções como essas que os afrorreligiosos considerem que a atuação de Exu, um trickster divino - ou seja, um transformador, comunicador e transportador supremo, onipresente e brincalhão —- é tão abrangente quanto necessária. Dizer que nada pode ser feito sem o intermédio desse agente cosmológico central equivale a assumir que tudo está simultaneamente envolto em "ironias míticas" e "prazeres sagrados" (Pelton, 1980). Se tudo tem muitas qualidades, no manejo de diferenças que nunca são inteiramente superadas, todos os gestos de aliança, cuidado, controle ou mediação que partem dos fiéis humanos buscam, evidentemente, a produção, manifestação ou atração dos lados mais favoráveis, vantajosos e prazerosos de cada ente ou de cada coisa. Como ponderava o velho Montaigne, "aprender a morrer", a pensar na morte todo o tempo, é também aprender simetricamente a aproveitar os dons da vida. Dizia ele que, no fim das contas, "o prazer é a meta da vida" (Montaigne, 1996: 92) e, ao mesmo tempo, que "a meta de nossa existência é a morte" (Montaigne, 1996: 94) ${ }^{14}$. 
É possível afirmar também, encarando a mesma questão por uma perspectiva complementar, que, além de manter, como seus ancestrais yorubás, esta "percepção da vida enquanto uma totalidade circular cujas faces tanto mascaram quanto desvendam umas às outras" (Pelton, 1980: 104), o povo de axé cultiva a perseverança por meio de uma temporalidade lenta e cíclica. Desde o aprendizado paciente, não formalizado, baseado no acúmulo de indícios e explicações parciais ao longo dos anos - aquilo que nos candomblés se chama "catar folha" (Goldman, 2005; Queiroz, 2019) — até a formação conjunta da pessoa ritual de um fiel, com seu otá, seus assentamentos, seu corpo e seu próprio orixá, entende-se que o tempo de se fazer uma coisa firme e durável (de se aprontar um ente) deve ser prolongado e gradativo. Estamos muito longe do tempo apocalíptico, acelerado e progressivo que caracteriza outros credos.

Tendo tudo isso em vista, o respeito às medidas locais ou às normas da OMS e a paciência demonstrada pela maioria dos afrorreligiosos ante a crise do coronavírus começam a ter algum caráter explicativo em relação à pergunta que iniciou este artigo. Tais cultos se adequaram satisfatoriamente à pandemia porque, neles, o tempo de cada coisa deve ser respeitado, pequenos ajustes entre a tradição e a imprevisibilidade de Exu precisam ser feitos constantemente e tudo pode ser reconfigurado, afinal, passando a ocupar outros lados.

Se o grande décepteur faz e refaz seus enredos "por meio de encadeamentos recíprocos de fragmentos de cadeias sintagmáticas provenientes de mitos" - e, eu acrescentaria, histórias, patógenos, realidades etc. — "distintos, quando não opostos" (Lévi-Strauss, 2004 [1967]: 179), os afrorreligiosos também sabem que, por meio de interações menos cósmicas e mais cotidianas, a rede interminável de mediações e adaptações criativas que os envolvem e que visa, no limite, ao ser-com-os-outros ou simplesmente ao estar junto (Heidegger, 2012 [1927]; Rabelo, 2012) confunde-se com a vida e com o próprio destino. Em resumo, até 0 porvir, a vontade soberana dos deuses ou uma tragédia de grandes proporções, como a pandemia da COVID-19, podem ser pacientemente alterados e afetados pela atenção constante e pelo cuidado humano. Sendo assim, finalizo meu texto com breves comentários, forçosamente inconclusivos, a respeito de alguns gestos de cuidado - muito eficazes, aliás, tanto em relação aos deuses e ancestrais quanto a questões de saúde coletiva e individual — dos meus parceiros de pesquisa frente à pandemia.

\section{AVAMUNHA}

\section{NÃO SE DIRIJAM AO BARRACÃO}

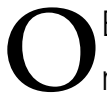

Bembé de 2020 foi parcialmente realizado em respeito aos "rituais da tradição com a nossa ancestralidade e os orixás" (Chaves, 2020), mas em caráter enlutado. Tal como informa um comunicado que circulou por Santo Amaro no início de maio, as oferendas fo- 
ram arreadas numa praça vazia, sem "aglomerações, foguetes e atabaques" (Chaves, 2020). Além dessa transformação na performance ritual, a simbologia sacrificial da cerimônia sofreu uma inflexão significativa. Ao invés de festejar a vida, a comida ritual serviu para "dar satisfação aos ancestrais" (Pereira e Portela, 2020). 0 comunicado - assinado por Pai Pote, sacerdote responsável pela festa nos últimos anos - termina, significativamente, com um apelo enfático aos cidadãos santo-amarenses: "Diante do exposto, informamos à população que FIQUE EM CASA, NÃO SE DIRIJAM AO BARRACÃO, o povo de santo agradece a compreensão de todos" (Chaves, 2020, ênfase no original).

Na live já mencionada do dia 14 de maio, Mãe Manuela trouxe, ainda, outros elementos que nos permitem pensar tais atitudes cautelosas ao colocar o coronavírus e a pandemia no meio de um enredo maior, de ressonância mítica, que associa a doença à ação antrópica, repartindo, contudo, as competências e responsabilidades pela crise sanitária entre religiosos e cientistas, por um lado, e, por outro, entre os interesses humanos e as atividades da Morte:

Então, eu sei que os terreiros não vão abrir porque lá não é instituto de ciência pra descobrir doença científica. Porque a doença, tudo leva a crer que é uma doença causada e criada pelo ser-humano. Então o sopro do mundo, hoje, é Iku. Quem manda no mundo é Iku.

E, mais adiante:

Então, o que acontece? É quando o ser-humano eleva os pensamentos para além dos seus pensamentos, é quando o ser-humano é manuseado pelos seus ideais, pelos seus interesses. Hoje, a pandemia é criada pelo ser-humano e quando o ser-humano cria, Iku vem à Terra. É o sopro da Morte (Chaves, 2020).

Em outras palavras, a COVID-19 e a crise sanitária, assim como "suas divindades, são, ao mesmo tempo, construídas, fabricadas, 'assentadas' e são, por consequência, reais" como dizia Latour a respeito do candomblé brasileiro (2002: 20, grifo do autor). Desconstruí-las, desfabricá-las e desassentá-las requer prudência empírica, atenção aos detalhes e tempo.

Yá Vera Soares dizia o seguinte, do outro lado do país, naquela audiência pública que assisti em meados de março — ou seja, logo no início da crise sanitária, antes mesmo da adoção das primeiras medidas de controle oficial da pandemia — e com palavras ainda mais próximas às formulações de Latour: "tá aí o vírus, matando um por um, e todo mundo sabe como ele foi praticado, como ele foi construído... então, a brincadeira acabou!" (TV ALRS, 2020). Em contrapartida, o bom humor resignado, mas inabalável de Pai Tiago, sempre tomando o chimarrão dele em sua casa, na Zona Sul de Porto Alegre, e tentando levantar cestas básicas para auxiliar a comunidade negra porto-alegrense, mostrava uma face mais serena desses mesmos expedientes adaptativos. 
A premência em estabelecer vínculos e alianças, ainda mais numa situação tão extraordinária e ameaçadora, ajuda a explicar, também, o ímpeto do meu trabalho de campo online, junto à confiança e à afetuosidade que o tem atravessado. De todas as minhas interações de pesquisa de 2020, escolho, para finalizar, uma única imagem, um momento etnográfico (Strathern, 1999) comovente que sintetiza, de forma particularmente concreta, materialmente irredutível (Pietz, 1985), todos os temas deste ensaio, do respeito ao tempo à urgência, da diferença às mediações, da atenção à morte à construção diligente das relações e dos corpos. Falei com Darlei via chamada de vídeo no WhastApp pela primeira vez no dia 02 de maio. Ele estava triste. 0 Bembé daquele ano seria atípico e provavelmente não contaria com a sua presença. Além disso, a árvore mais antiga do centro de Santo Amaro, uma sumaúma centenária, havia caído após uma chuva forte e, com os temporais, o rio Subaé, que passa pela cidade, não parava de subir. Darlei normalmente participa de todo o Bembé, tocando atabaque nas noites sucessivas da festa.

Naquela ocasião, ele apoiou o celular num móvel para poder trabalhar numa escultura enquanto conversava comigo. Na minha frente, através da mediação dos nossos aparelhos eletrônicos, pude flagrar o momento no qual a morte - a escultura consistia nos emblemas do orixá Logun Edé15, feitos com uma série de linhas e pregos afixados num dos cepos retirados da árvore - , o desânimo e a ansiedade eram visivelmente reconfigurados por suas mãos (Figura 2).

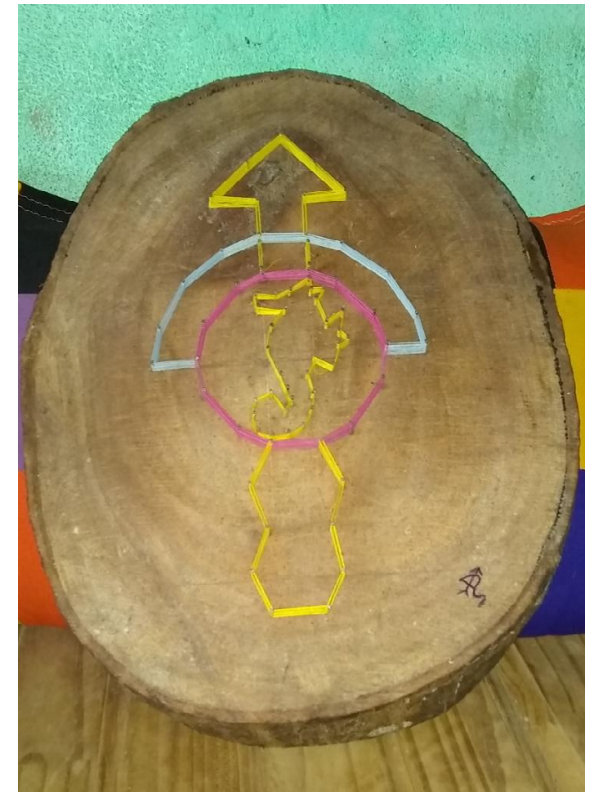

Figura 2 - Emblemas de Logun Edé, Darlei Sacramento. Imagem recebida via WhatsApp no Dia das Mães, 10 de maio de 2020. 
Ele fazia, naquele instante, daquele pedaço de madeira uma dádiva, um presente para sua mãe biológica e, simultaneamente, para o orixá dela. A velha sumaúma que havia presenciado o primeiro Bembé, no ano distante de 1889, voltava, assim, ao tempo histórico, transmutada num dispositivo singular que permitia o manuseio eficaz de tensões, vírus, enchentes, ancestrais e pavores, uma vez que "o melhor que se pode fazer sob o domínio de tais forças, é persistir por um pouco mais de tempo, tomando algumas precauções a mais, tomando cuidado" (Latour, 2002 [1996]: 96). Darlei transferia e reconduzia tudo isso, por meio de movimentos precisos e do manejo de entes-objetos ou quase-objetos, para o domínio das relações doméstico-afetivas, tornando-os, enfim, concebíveis numa escala humana.

Conflitos de interesse: nada a declarar.

Fonte de financiamento: nenhuma.

\section{NOTAS}

1 Toque rápido utilizado para abrir e fechar as festas públicas de candomblé.

2 Guardadas suas diferenças, o batuque gaúcho, o candomblé e a umbanda estão entre as principais religiões ou cultos normalmente chamados de "afro-brasileiras(os)", "de matriz africana" etc. A bibliografia sobre o tema é imensa. Indico, apenas a título de localização, a leitura de Verger (1981 [1951]), Santos (1976 [1972]) e Johnson (2002). Sobre o batuque afro-rio-grandense, especificamente, cf. Corrêa (1992) e Oro (1994). Utilizo as expressões "povo de axé", "povo de santo" ou "afrorreligiosos" para referir-me genericamente aos adeptos dessas religiões todas.

3 Para uma discussão aprofundada sobre o cuidado no candomblé, cf. Rabelo (2014) e Moreno Neto (2017). Embora ambos os trabalhos tenham sido produzidos na antropologia, suas perspectivas são diferentes e complementares. Enquanto Míriam Rabelo enfatiza os cuidados religiosos, as relações de zelo e atenção que vinculam os deuses e os fiéis, José Luiz Moreno Neto, que também é pai de santo e médico, privilegia os cuidados corporais e as concepções de saúde das comunidades de terreiro.

4 Cf. Lima (2010). Nações são segmentos cultuais distintos, porém inter-relacionados, por meio dos quais os fiéis dessas religiões subdividem-se. Seus nomes - Jeje, Angola etc. — derivam dos etnônimos utilizados no contexto do tráfico negreiro. 
5 As noções de corpo, pessoa e persona utilizadas neste artigo são evidentemente devedoras das ideias de Marcel Mauss e devem ser entendidas, portanto, como fatos morais e/ou categorias do pensamento e não apenas (ou não necessariamente) como elementos biológicos. Cf. Mauss (2003 [1950]: 367-398).

6 Cf. Queiroz (2019) e Rabelo (2014). Enredo é outro conceito operante na maioria das religiões afro-brasileiras. Refere-se às ligações entre coisas aparentemente díspares e que, no entanto, se cruzam no interior de um mito ou de um rito, influenciam-se mutuamente e guardam uma relação de homologia. Além de serem frequentemente contraintuitivos, os enredos são revelados paulatinamente aos fiéis, passando pela política de transmissão do conhecimento baseada na observação paciente que será tematizada ao fim deste artigo.

7 Apesar disso, não farei nenhuma discussão teórica a respeito das potencialidades e dos limites de uma pesquisa virtual. Cf., nesse sentido, Capponi e Araújo (2020), artigo recém-publicado que trata, precisamente, da relação entre afrorreligiosos, a COVID-19 e os meios digitais.

8 Como, no batuque, Exu e Bará são considerados equivalentes, mas a recíproca não é exatamente verdadeira, uma vez que, no candomblé baiano Bará é tido como uma das qualidades dessa divindade, neste artigo utilizo o termo "Exu" para falar dessa entidade de modo geral e "Bará" para me referir especificamente ao contexto gaúcho. As qualidades de um orixá correspondem aos seus atributos distintivos ou às diferentes formas (velho, novo, irascível, apaziguador, masculino, feminino etc.) que eles podem assumir em seus mitos. Cf. Verger (1981) e Dos Anjos (2008).

9 Cf. Sansi (2005), Dos Anjos (2008) e Queiroz (2019). Conforme indiquei anteriormente, os corpos e as pessoas dos fiéis e das próprias divindades devem ser produzidos cuidadosamente nessas religiões. Para tanto, eles precisam ser assentados em determinados lugares previamente consagrados. Os assentamentos incluem pedras (otás, okutás) e outros objetos que servem de suporte para os fundamentos (áwo) que mantêm vivo/em circulação a força (axé) de alguém.

10 "Casa" em yorubá - língua ritual de origem oeste-africana utilizada em certas religiões afro-brasileiras (Cf. Beniste 2011). Esse termo designa a área construída dos terreiros ou das casas de religião, seus arredores e, por extensão, suas comunidades religiosas que são permeadas por laços de parentesco tanto religioso quanto biológico. Quase todos os meus parceiros de pesquisa, na Bahia ou no Rio Grande do Sul, pertencem a nações que utilizam o idioma yorubá em suas atividades sagradas.

11 Orin (cantiga) em yorubá dedicada a Exu. Tradução própria.

12 Décepteur é o termo utilizado na obra de Claude Lévi-Strauss a partir das Mitológicas, em substituição a trickster, denominação anterior, empregada, por exemplo, na citada A Estrutura 
dos Mitos. Esse termo foi traduzido no Brasil por Beatriz Perrone-Moisés como "deceptor" e, posteriormente, "enganador". Embora esta segunda formulação tente, segundo a própria tradutora, manter a ambiguidade desses personagens que "podem surpreender positivamente" (Perrone-Moisés, 2004 [1964]: 13), prefiro manter o original, por acreditar que a noção de "engano" ainda mantém uma "ressonância negativa" (Perrone-Moisés, 2004 [1964]: 13), em português, e um caráter intencional nem sempre presente em seus mitos. Tratando-se das Mitológicas, acredito o melhor paralelo para captar a agência inesperada, equívoca ou traiçoeira dos décepteurs deve ser buscado nas cadências deceptivas da música tonal ocidental - estruturas harmônicas que parecem pedir uma determinada sequência ou resolução, mas que, ao frustrarem repentinamente as expectativas do ouvinte, terminam provocando um recomeço inusitado ou a retomada brusca de temas musicais anteriores.

13 Emprego essa terminologia sem a pretensão de iniciar uma discussão propriamente filosófica. 0 mesmo vale para o paralelo que será feito, a seguir, entre as proposições de um dos ensaios de Montaigne, "De como filosofar é aprender a morrer" (Montaigne 1996: 92-105), e as atitudes que o povo de santo costuma adotar ante a morte.

14 Montaigne joga, no texto original, com os diversos sentidos de duas palavras relativamente próximas em francês: bout (fim, ponta) e but (meta, destino). Sendo assim, os trechos poderiam ser traduzidos alternativamente como "o prazer é o fim da vida" e "o fim de nossa existência é a morte".

15 Divindade que ora assume uma qualidade masculina, ora uma feminina, sendo associada à pesca. A escultura de Darlei combina vários de seus atributos: o ofá (arco e flecha), o cavalo-marinho e os favos de mel. Logun é cultuado tanto no candomblé quanto no batuque.

\section{REFERÊNCIAS BIBLIOGRÁFICAS}

ALMEIDA, R.; GUERREIRO, C. Bolsonaro e igrejas evocam liberdade religiosa sem considerar bem-estar no Coronavírus. Folha de São Paulo, São Paulo, 10 abr. 2020.

BENISTE, J. Dicionário Yorubá — português. Rio de Janeiro: Bertrand Brasil, 2011.

CAPPONI, G.; ARAÚJO, P. Occupying new spaces: the "digital turn" of Afro-Brazilian religions during the COVID-19 outbreak. International Journal of Latin American Religions, v. 4, n. 2, p. 250-258, 2020. https:// doi.org/10.1007/s41603-020-00121-3

CARDOSO, V.; HEAD, S. Matérias nebulosas: coisas que acontecem em uma festa de Exu. Religião e Sociedade, Rio de Janeiro, v. 35, n. 1, p. 164-192, 2015. https://doi.org/10.1590/0100-85872015v35n1cap08

CHAVES, J. (Pai Pote). Comunicado à população de Santo Amaro: Bembé do Mercado e Pandemia (panfleto). Santo Amaro: Associação Beneficente Bembé do Mercado de Santo Amaro, 08 maio 2020. 
CORREAA, N. O Batuque do Rio Grande do Sul. Porto Alegre: EDUFRGS, 1992.

DOS ANJOS, J. C. A filosofia política da religiosidade afro-brasileira como patrimônio cultural africano. Debates do NER, Porto Alegre, v. 9, n. 13, p. 77-96, 2008. https://doi.org/10.22456/1982-8136.5248

GOLDMAN, M. Formas do saber e modos do ser: observações sobre multiplicidade e ontologia no candomblé. Religião e Sociedade, Rio de Janeiro, v. 25, n. 2, 2005.

GOLDMAN, M. Histórias, devires e fetiches das religiões afro-brasileiras: ensaio de simetrização antropológica. Análise Social, Lisboa, n. 190, 105-137, 2009.

GOLDMAN, M. O Dom e a Iniciação Revisitados: o dado e o feito em religiões de matriz africana no Brasil. Mana, Rio de Janeiro, v. 18, n. 2, p. 269-288, 2012. https://doi.org/10.1590/S0104-93132012000200002

HEIDEGGER, M. Ser e Tempo. Campinas/Petrópolis: UNICAMP/Vozes, 2012 [1927].

JOHNSON, P. Secrets, gossip and gods: the transformation of Brazilian candomblé. Oxford: Oxford University Press, 2002.

LATOUR, B. Reflexão sobre o culto modern dos deuses fe(i)tiches. Florianópolis: EDUSC, 2002 [1996].

LÉVI-STRAUSS, C. A estrutura dos mitos (1955). In: LÉVI-STRAUSS, C. Antropologia estrutural. São Paulo: Cosac Naify, 2008.

LÉVI-STRAUSS, C Do mel às cinzas. São Paulo: Cosac Naify, 2004 [1967]. (Mitológicas, v. 2).

LIMA, V. C. Lesse Orixá: nos pés do santo. Salvador: Corrupio, 2010.

MACHADO, A. Bembé do Largo do Mercado. 2009. 117f. Dissertação (Mestrado multidisciplinar) Universidade Federal da Bahia, Salvador, 2009.

MACHADO, C. F. Lugares e objetos de memória no batuque gaúcho. Religião e Sociedade, Rio de Janeiro, v. 35, n. 1, p. 107-120, 2015. https://doi.org/10.1590/0100-85872015v35n1cap05

MARTINS, T. (Pai Tiago); SORDI, R. O Batuque em época de pandemia (live). Jornal Grande Axé, Porto Alegre, 21 abr. 2020. Disponível em: <https://www.facebook.com/jornalGA/videos/ 1506771179500451/>. Acesso em: 02 dez. 2020.

MATEUS, S. Colunismo Social dos Terreiros Afro-Gaúchos. In: COLVERO, R. et al. (orgs.). Interdisciplinaridade nas ciências humanas. Jaguarão: CLAEC, 2017. p. 252-266.

MATTOS, H.; ABREU, M. A História como Performance. In: MAUAD, A et al. (orgs.). História Pública no Brasil. São Paulo: Letra e Voz, 2016. p. 221-235.

MAUSS, M. Sociologia e antropologia. São Paulo: Cosac Naify, 2003 [1950].

MONTAIGNE, M. De como filosofar é aprender a morrer. In: MONTAIGNE, M. Ensaios. São Paulo: Nova Cultural, 1996 [1588]. p. 92-105.

MORENO NETO, J. L. O Cuidado nos Candomblés Jeje Savalu. Tese (Doutorado em Antropologia) Universidade Federal da Bahia, Salvador, 2017.

PELTON, R. The Trickster in West Africa: a study of mythic irony and sacred delight. Berkeley: University of California Press, 1980. 
PERRONE-MOISÉS, B. Traduzir as Mitológicas. In: LÉVI-STRAUSS, C. O Cru e o cozido. São Paulo: Cosac Naify, 2004 [1964]. (Mitológicas, v. 1).

PIETZ, W. The Problem of the fetish, I. RES: Anthropology and Aesthetics, Cambridge, n. 9, p. 5-17, Spring 1985.

PORTO ALEGRE. Decreto $n^{\circ} 20.534$, de 31 de março de 2020 - Decreta o estado de calamidade pública e consolida as medidas para enfretamento da emergência de saúde pública de importância internacional decorrente do novo Coronavírus (COVID-19), no município de Porto Alegre. Porto Alegre: Prefeitura Municipal/ Procuradoria-Geral do Município, 2020.

PEREIRA, M. (Mãe Manuela); PORTELA, A. Religiões de Matriz Africana: combate à intolerância religiosa —Parte 2 (live). Santo Amaro, 14 mai. 2020. Disponível em: <https://www.youtube.com/watch?v=q8TvrBHGMf4>. Acesso em: 03 dez. 2020.

QUEIROZ. V. O corpo do patriarca: uma etnografia do silêncio, da morte e da ausência. Mana, Rio de Janeiro, v. 25, n. 3, p. 743-776, 2019. http://dx.doi.org/10.1590/1678-49442019v25n3p743

RABELO, M. Construindo Mediações nos Circuitos Afro-Brasileiros. In: STEIL, C.; CARVALHO, I. (orgs.). Cultura, percepção e ambiente: diálogos com Tim Ingold. São Paulo: Terceiro Nome, 2012. p. 103-119.

RABELO, M. Enredos, feituras e modos de cuidado: dimensões da vida e da convivência no candomblé. Salvador: EDUFBA, 2014.

SIQUEIRA, P. "Ser afetado", de Jeanne Favret-Saada. Cadernos de Campo, São Paulo, v. 13, n. 13, 2005 [1990]. https://doi.org/10.11606/issn.2316-9133.v13i13p155-161

STRATHERN, M. O efeito etnográfico. In: STRATHERN, M. O Efeito Etnográfico. São Paulo: Cosac Naify, 2014 [1999].

VIVEIROS DE CASTRO, E. 0 nativo relativo. Mana, Rio de Janeiro, v. 8, n. 1, p. 113-148, 2002. https://doi. org/10.1590/S0104-93132002000100005

ORO, A. As religiões afro-brasileiras do Rio Grande do Sul. Porto Alegre: EDUFRGS, 1994.

ORO, A. et al. A tradição do Bará do mercado. Porto Alegre: PMPA/SMC/CMEC, 2007.

SANSI, R. The hidden life of stones. Journal of Material Culture, Londres, v. 10, n. 2, p. 139-156, 2005.

SANSI, R. Fazer o Santo: dom, iniciação e historicidade nas religiões afro-brasileiras. Análise Social, Lisboa, v. XLIV, n. 190, p. 139-160, 2009.

SANTOS, J. O Nàgô e a Morte. Petrópolis: Vozes, 1976 [1972].

TURNER, V. The Forest of Symbols. Ithaca: Cornell University Press, 1970 [1969].

TV ALRS. Audiência pública sobre o inventário dos bens culturais que compõem a condição de patrimônio cultural do Mercado Público de Porto Alegre. Canal ALRS. Porto Alegre, 11 abr. 2020. Disponível em: <https:// www.youtube.com/watch?v=lcCmyYVhFK0\&t=6263s>. Acesso em: 19 dez. 2020.

VERGER, P. Orixás. Salvador: Corrupio, 1981 [1951]. 